\title{
Cuerpos de mujeres, significados de género y límites simbólicos en la gran minería en Chile
}

\author{
Pamela Caro Molina \\ Universidad Santo Tomás, Santiago, Chile. \\ Email:pamelacaro1@santotomas.cl \\ Helena Román Alonso \\ Universidad Santo Tomás, Santiago, Chile. \\ Email: hroman@santotomas.cl \\ Lorena Armijo Garrido \\ Universidad Santo Tomás, Santiago, Chile. \\ Email: lorenaarmijoga@santotomas.cl
}

\begin{abstract}
Resumen: El artículo busca develar los modos en que trabajadoras de faenas mineras significan sus cuerpos, como barrera simbólica que produce segregación, discriminación y marginación, interpretados desde las nociones de violencia simbólica, valencia diferencial de los sexos, desigualdad de género, precariedad y estigma social. Desde una metodología cualitativa, a través del análisis de 31 entrevistas a operarias y supervisoras, se interpretan y triangulan percepciones en torno a trayectorias y experiencias de relacionamiento de género en la gran minería. La corporalidad como límite y violencia se expresa en la sexualización de sus cuerpos; juicio e infravaloración por la menor fuerza física; rechazo, estigmatización y banalización al cuerpo reproductivo; así como en exigencias por personificar rasgos hegemónicos masculinos para inspirar respeto, pero sin «perder feminidad» clásica, provocando desgaste y confrontación.
\end{abstract}

Palabras claves: cuerpos de mujeres; faenas mineras; violencia simbólica; barreras de género.

\section{Women's bodies, gender meanings and symbolic limits in large-scale mining in Chile}

Abstract: This article seeks to unveil the ways in which women mining workers signify their bodies, as a symbolic barrier that produces segregation, discrimination and marginalization, interpreted from the notions of symbolic violence, differential value of the sexes, gender inequality, precariousness and social stigma. Using a qualitative methodology, through the analysis of 31 interviews with operators and supervisors, perceptions are interpreted and triangulated around trajectories and experiences of gender relations in large-scale mining. Corporality as a limit and violence is expressed in the sexualization of their bodies; judgment and undervaluation due to less physical force; rejection, stigmatization and trivialization of the reproductive body; as well as in demands for personifying hegemonic male traits to inspire respect, but without «losing femininity", which is classic, causing distress and confrontation.

Keywords: women’s bodies; mining operations; symbolic violence; gender barriers.

\section{Corpos de mulheres, significados de gênero e limites simbólicos na grande mineração no Chile}

Resumo: O artigo procura revelar as maneiras pelas quais as trabalhadoras da mineração entendem seus corpos, como uma barreira simbólica que produz segregação, discriminação e marginalização, interpretado desde as noções de violência simbólica, valência diferencial dos sexos, desigualdade de gênero, precariedade e estigma social. Desde uma 
metodologia qualitativa, a través da análise de 31 entrevistas com mulheres operarias e supervisoras, se interpretam e triangulam percepções sobre as trajetórias e experiências de relações de gênero na grande mineração. A corporalidade como limite e violência se manifesta na sexualização de seus corpos; juizo e subavaliação pela menor força física; repúdio, estigmatização e banalização do corpo reprodutivo; bem como nas exigências por personificar traços hegemônicos masculinos no corpo femenino para intentar impor respeito, mas sem «perder a feminidade» tradicional, causando desgaste e confronto.

Palavras-chave: corpos de mulheres; atividades mineiras; violência simbólica; barreiras de gênero.

\section{Introducción}

En la última década, Chile ha evidenciado, no sólo un crecimiento en participación laboral de mujeres en la gran minería, aun cuando siguen estando subrepresentadas con menos del 8,5\% global (CCM, 2019); sino que también se ha producido una alegoría retórica en ambientes gremiales y gubernamentales para develar su presencia, y con ello mostrar que las mujeres «si pueden» estar en espacios no tradicionales. Sin embargo, este deseo se enfrenta a realidades complejas, de desigualdad de poder, estigmatización, segregación, violencia simbólica y sufrimiento social femenino.

En el pasado reciente, la presencia femenina en minería era explícitamente indeseada, pues podría traer mala suerte a la actividad. Creencia incluso refrendada por la propia regulación laboral, a través del Código del Trabajo. Dicha legitimación incidió en generar una cultura interna que reforzó la exclusión femenina mediante un imaginario de mitos y supersticiones (Campos, et al., 2016). Recién en 1996 se deroga el artículo 15 que establecía que «las mujeres no pueden ser ocupadas en labores mineras subterráneas ni faenas calificadas como superiores a sus fuerzas o peligrosas para las condiciones físicas o morales propias de su sexo». Es decir, se atentaba contra la libertad de trabajo de las mujeres, poniéndolas en la misma posición que menores de edad.

Eliminándose dicha prohibición, persiste en las representaciones sociales del entorno minero, rechazo, desprecio y visión excluyente a su presencia, con énfasis en áreas operativas o mantención, por considerar que no son «lugares para ellas». En el pasado, su participación estaba limitada a funciones tradicionalmente feminizadas, como aseo, preparación de alimentos, administrativas o secretarias (Angelcos, 2015; Ruiz, 2013).

El presente artículo aborda como problema, los modos en que el cuerpo de las mujeres es significado, desde la perspectiva de operarias y supervisoras de faenas mineras del centro y norte de Chile, como barrera simbólica de marginación. Desde la dimensión del cuerpo, buscamos mostrar cómo las mujeres experimentan formas violentas y expuestas a juicio ambiental por su condición sexuada, incluyendo la forma en que se mueven, se presentan estéticamente frente a otros (visten y/o maquillan), se relacionan con sus pares (mujeres y hombres) o hablan, entre otros aspectos en los que se expresa una corporeidad cuestionada, rechazada y exigida. Recogemos resultados empíricos que abordan procesos de inclusión de mujeres en minería, así como conflictos y oportunidades que se generan en dicho tránsito, analizados desde el género e interseccionalidad.

\section{Características del entorno laboral minero}

Investigaciones recientes abordan el impacto de las transformaciones de las jornadas de trabajo en las vidas cotidianas y familias de las mujeres en minería (Kublock, 1992,1998; Ibáñez, 2008; Barrientos et al., 2009; Salinas, Barrientos y Rojas, 2012). Constatando la existencia de una cultura hostil, de carácter hegemónico masculino y códigos homosociales (Salinas y Romani, 2014, 2015; Salinas y Cordero, 2016; Pavez y Hernández, 2014), en el que se perpetúan discursos discriminatorios hacia las mujeres (Salinas, Barrientos y Rojas, 2012; Jiménez, Rojas y Troncoso, 2014), que ofrece resistencias ante su incorporación y en la que se reproducen desigualdades y jerarquías de género (Ibáñez, 2008: 90). En operaciones y mantención, en las que con frecuencia son las únicas mujeres en el equipo o turno, se complejiza su estadía y se exacerban manifestaciones de devaluación (Caro et al., 2019). 
Pese a la existencia de acciones positivas a favor de la integración, las mujeres siguen experimentando formas de violencia (Angelcos e Ísola, 2017) fruto de una cultura fuertemente arraigada en la dominación masculina (Bourdieu, 2000) y desiguales relaciones de poder. El esfuerzo por ser equiparadas con sus compañeros hace que algunas, para no perder femineidad, refuercen estereotipos de género tradicionales, que reproducen su segregación (Salinas y Romaní, 2016).

El trabajo en faenas, asociado a sistemas de turnos excepcionales, genera una dislocación entre trabajo y descanso, y enfrenta a las personas a experimentar distanciamiento familiar (Barrientos, et al., 2009). Las excesivas demandas físicas que ha tenido en la historia la actividad, acompañada de riesgos para la salud y condiciones ambientales extremas (oscilación térmica, nieve, altura geográfica, entre otros) fueron pensadas como constricciones legítimas que la concibieron como un trabajo no apto para mujeres (Ayala, 2012).

\section{El cuerpo femenino en minería: dominación masculina, sexualización y devaluación}

Las desigualdades entre hombres y mujeres se han focalizado en la forma en que la percepción de las diferencias se ha convertido en construcción de una jerarquía valórica, que las deja sistemáticamente en situación de subordinación y que ha sido reproducida por el sistema (hetero) patriarcal vigente (Curiel y Falquet, 2005). Como pacto interclasista y metaestable, a través del cual los hombres se han instituido como sujetos del contrato social y mediante el que aseguran su dominio, ha comprendido el uso de la violencia y el control del cuerpo (Amorós, 1994). La construcción patriarcal se fundamenta en la apropiación histórica de los hombres de la capacidad fecundativa y goce de la sexualidad de las mujeres y, por tanto, de sus cuerpos (Héritier, 2007). Un tal carácter «natural», casi «evidente», es una de esas expresiones cotidianas y violentas de la materialidad de la apropiación de la clase de las mujeres por parte de la clase de los hombres (Guillaumin, 2005).

La corporalidad juega un papel importante en la construcción de la desigualdad. Así, diferencias en la piel o voz, rasgos claramente observables, se asimilan a las cualidades de sumisión y pasividad atribuidas como innatas a las mujeres. La apropiación es moldeada por las estructuras de dominación que las producen, convirtiéndose en violencia simbólica cuando en el mercado de bienes simbólicos son tratadas como objetos que circulan, colocándolas en un estado permanente de inseguridad corporal, es decir, de dependencia simbólica, donde existen por y para la mirada de los demás, como objetos acogedores y femeninos, así como sonrientes, simpáticas o atentas (Bourdieu, 2000). Algo similar sucedería con la fuerza física masculina, la que históricamente se convirtió en un elemento de coacción para confinar a las mujeres al rol de procreadoras domésticas, excluidas del conocimiento y esfera política (Héritier, 2007), negando legitimidad a su presencia en otros lugares.

Las percepciones acerca de la sexualidad son también reflejo de la dominación masculina (Bourdieu, 2000). Uno de los elementos más fuerte e invariable de la valencia diferencial de los sexos, que otorga una supremacía de reconocimiento a lo masculino (Héritier, 2002), radicaría en la idea de legitimidad de la pulsión sexual masculina, la que no debe tener obstáculos ni oposiciones (Héritier, 2007). Desde dichas representaciones, los cuerpos de las mujeres que acceden a espacios masculinos como la minería, estarían disponibles y despojados de valor, en tanto salen de los espacios y roles a los que están relegadas de acuerdo con sus características fisiológicas.

La erotización y mercantilización del cuerpo femenino por medio de la publicidad, obedece a la creencia social que dichos cuerpos pertenecen «a todos los hombres» (Héritier, 2007; Pavez, 2018). Las imágenes, como mecanismos que promueven la dominación masculina a través de la sexualización, generan una cosificació e infravaloración de las mujeres (Goffman, 1978). También se usan recursos para el consumo femenino, bajo el argumento de suscita el deseo masculino, que es el que les hace sentir que ellas existen.

Butler (2015) hace referencia a la performatividad de género, para sostener que se nos educa desde normas culturales, según seamos asignados hombre o mujer, y configura nuestro modo de vida corporeizado. Se nos designa un nombre y se nos aplica un género, antes que entendamos cómo las normas de género actúan sobre nosotros/as y nos determinan, seamos capaces de reproducir esas normas como opción escogida. La 
elección aparece más tarde en el proceso de la performatividad, considerando que existen condiciones y posibilidades de actuación y deliberación.

Sin embargo, la condición de precariedad de género se materializa en un elevado riesgo de maltrato, para quienes no viven su género de acuerdo con normas socializadas. Dichas normas intervienen en los modos y grados en que podemos aparecer en el espacio público y en cómo esas diferencias se convierten en instrumentos de la política sexual (Butler, 2015). De ahí que las faenas mineras se transformen en escenarios para evidenciar la tensión que genera la representación del cuerpo de las mujeres que desafía normas de género, donde se conjugan aceptación adaptativa y rechazo.

Desde el enfoque dramatúrgico, dichos escenarios son una situación interactiva en que hombres y mujeres tratan de mostrarse con una determinada imagen o personaje que resulte agradable, para ser aceptados (Goffman, 1959, 1970). Con el tiempo, van incorporando sentimientos positivos vinculados a las imágenes de sí mismo según el valor social conferido (Charon, 1992).

Los cuerpos se exponen en espacios de interacción como si se tratara de escenarios, articulando lo que se desea mostrar y lo que no, según las conveniencias sociales. Modales o maquillaje, son formas de disciplinar el cuerpo y hacerlo más presentable (Goffman, 1970). Algunas utilizan el cuerpo a su favor, buscando en el piropo la aceptación; otras buscan protección, asumiendo una imagen de hermana, hija o madre; y también están quienes se «masculinizan», (Caro at al, 2019; Stefoni, 2005; Rojas, 2014). En cualquier caso, se genera incomodidad o miedo ante la sexualización o acoso, y paradójicamente también ante la pérdida de femineidad tradicional (Angelcos e Isolda, 2017).

\section{Cuerpos, género y reproducción}

El género, entendido como elemento constitutivo de relaciones sociales basadas en las diferencias que distinguen a los sexos (Scott, 2005; Rubin, 1970), y construcción histórica, permite cuestionar explicaciones naturalizadas y estereotipadas, y reconocer el carácter elástico de la división sexual del trabajo, que está en el centro de las relaciones de poder que se estructuran entre hombres y mujeres (Hirata y Kergoat, 1997).

Desde la teoría feminista, la categoría género constituye una herramienta para visualizar cómo la dominación masculina se articula en discursos de subordinación que generan diferencias en las relaciones simbólicas de poder (Lamas, 1986; Scott, 2008). Jerarquía o asimetría con profundas raíces históricas que implica, no solo elementos simbólicos, sino también estructurales, normativos e identitarios (Bogino y Fernández-Rasines, 2015).

Bourdieu (2000) analiza la división jerárquica de los sexos, señalando que el sistema de las oposiciones fundamentales se ha conservado, incluso después de la entrada de las mujeres al trabajo remunerado. La división entre hombres y mujeres sigue organizándose en torno a la oposición entre interior (doméstico) y exterior (trabajo productivo), aun cuando la frontera se ha desplazado (Arendt, 1958), pero sin anularse. El concepto de habitus (Bourdieu, 1996) ayuda a explicar la división jerárquica de los sexos, adquirida por la socialización, entendida como sistema de categorías de percepción y acción, legitimada en costumbres, discursos y prácticas, que, a lo largo de la historia, ha otorgado a lo masculino una posición de mayor poder y reconocimiento. Los habitus se inscriben en cuerpos socializados, a través de una sumisión inmediata y pre reflexiva, que no descansa en una decisión deliberada de una conciencia ilustrada, pues los tipos de conductas cotidianas de hombres y mujeres se enmarcan en una situación conformada por una totalidad dotada de sentido, en una anticipación casi corporal, capaz de producir una respuesta adaptada que, sin ser jamás la simple ejecución de un plan, se presenta como una totalidad integrada e inmediatamente inteligible (Ibid, 1996).

La forma en que la reproducción femenina y maternidad se despliega como construcción cultural, ha implicado reglas y obligaciones. En el modelo de dominación masculina, las mujeres tienen mayor valor cuando están en edad reproductiva y/o han sido madres. La maternidad las hace ser reconocidas (Héritier, 2007). Pero al mismo tiempo, las castiga en el espacio del trabajo y se confronta de manera compleja y violenta en lo público (Riquelme, 2011; Héritier, 2007). 
El cuerpo femenino reproductivo, no en sí mismo, sino en el contexto relacional laboral masculinizado de la minería, puede verse como elemento estigmatizador, en tanto actúa como atributo que reduce a un estatus desacreditado. El estigma puede darse a partir de diferencias físicas, por la apreciación de deficiencias de carácter o pertenencias grupales que genera discriminación, porque se es alguien que no es visto como igual (Goffman, 1970).

En faenas mineras, normas y rituales establecidos en torno a la hegemonía masculina convierten la maternidad en un estigma, tanto para las que deciden ser madres como para las que no. La reproducción, como dimensión de dominación política, es usada para limitar la presencia de las mujeres en el mercado de trabajo, actuando como «castigo» en materia de estabilidad, igualdad salarial y valoración (Minerals Council of Australia, 2013).

\section{Metodología}

Las investigaciones base de este artículo recurrieron al paradigma interpretativo, sustentado en un diseño metodológico cualitativo (Ruiz, 2003; Tarrés, 2004), utilizando como principal técnica la entrevista en profundidad, que permitió recoger percepciones que representan los significados y experiencias vinculadas al cuerpo de las mujeres en faenas mineras. Las percepciones permiten recuperar los sentidos vinculados con vivencias cotidianas, avizorar significaciones y construir un saber denso sobre lo social (Kornblit, 2004). Las entrevistas fueron una conversación cara a cara que posibilitó acceder a subjetividades, profundizar en su realidad social (Vela, 2004) y comprender sus perspectivas, expresadas con sus propias palabras.

Se analizaron 31 entrevistas a mujeres operarias y supervisoras en faenas o plantas mineras ${ }^{1}$. Fueron realizadas entre 2017 y 2019, grabadas en audio, transcritas y codificadas mediante el método de análisis de contenido. El muestreo fue intencionado por conveniencia, siguiendo la estrategia de bola de nieve (Ruiz, 2003). En todos los casos se salvaguarda el anonimato de las entrevistadas, ocupando nombres ficticios, a quienes se les invitó a participar previa firma de consentimiento informado.

\section{Resultados}

Los resultados evidencian la preeminencia de barreras simbólicas, más que legales o de infraestructura, que se expresan en conductas y actitudes culturales, relativas al argumento de la fuerza física, sobresexualización, discriminación y violencia sexual, estigma sobre el cuerpo reproductivo y exigencias confrontadas entre conductas estereotipadas masculinas y femeninas. Aspectos que forman parte del plexo de justificaciones a la marginación, segregación o exclusión, que se tensiona en la práctica con la presencia femenina contranormativa y contracultural.

\section{La fuerza física como límite para las mujeres en faenas mineras}

Uno de los discursos que ha justificado históricamente la exclusión femenina en áreas operativas es su menor fuerza física -en comparación con el promedio de los hombres-. Se asume que existen tareas que, por requerimiento de esfuerzo corporal o peligrosidad, no resultan apropiadas para las mujeres. Lo que es visualizado como límite para su presencia. Perciben que los hombres tienen un discurso «políticamente correcto» en relación con su participación en áreas administrativas, siendo reconocidas sus capacidades, pero en operaciones y mantención mina, se impone la diferencia física.

«Mira, encuentro más resistencia en la gente que lleva mucho tiempo en la empresa y que tiene bastante edad, trabajadores de operación... de trabajar con objetos pesados, andar en terreno, de minas rajos, subterráneas, plantas, fundición, refinería» (Cristina, supervisora, 42 años).

Los cuerpos biológicos de las mujeres son cuestionados por el entorno, considerados «débiles» para la minería y sujetos a juicio. Para la producción minera, las diferencias de sexo ligadas al cuerpo biológico son 
indicadas por las entrevistadas, como argumentos de exclusión. Entre estas se señala el que sean en promedio más bajas, más livianas y tengan menos fuerza de carga, lo que es refrendado por el Código del Trabajo. Estos cuerpos distintos, aun considerando la heterogeneidad entre mujeres, están representados como destinados y expuestos a cometer errores, ya que, no serían «naturales» para la ejecución de ciertas labores.

A lo que algunas responden reclamantes e insumisas frente a dichas desvalorizaciones. No obstante, aquellas de mayor trayectoria, relatan cómo el verse rodeadas de hombres, en tareas de requerimiento físico, ha supuesto esforzarse por demostrar que su cuerpo es acorde a las tareas asignadas, como por ejemplo «tirar pala» o levantar objetos pesados.

«Le dije sabes qué, que seamos mujeres no significa que seamos un turno débil, quizás vamos a tirar dos palas menos que tú, pero vamos a hacer el mismo trabajo» (Patricia, operaria, 46 años»).

Según los relatos, en la concepción masculina cuando hay mujeres en un turno, «hay uno menos», puesto que, en sus representaciones simbólicas, cuerpos de mujeres no logran ser equivalentes a cuerpos de hombres. Expresiones desde el prejuicio, pues no existe evidencia empírica que demuestre resultados menores por la menor capacidad de trabajo cuando hay mujeres en los equipos o turnos. En el mismo testimonio, paradójicamente, la reivindicación del derecho de ascender de posición se tensiona pues se compara con la figura del varón.

«Anda una mujer en el turno, anda uno menos. Porque en el fondo no puede hacer la misma pega ... Quiero subir de escala, pero ¿cómo me van a considerar si no me puedo comparar con un hombre?» (Carmen, operaria, 31 años).

Cumplir la exigencia física desde el cuerpo biológico no sería suficiente para lograr aceptación. Sigue prevaleciendo negación y cuestionamiento, por habitar un espacio y ejecutar tareas que resultan contranormativas. Señalan, deben acudir a diversas estrategias para superar las 'faltas' acusadas y por las que son miradas y enjuiciadas.

«Te sentías observada, sabías que cuando ibas a meter pala, todos a tu alrededor te iban a estar mirando. Si lo hacías mal, era chuta, te veías como forzada a tener que hacer siempre las cosas bien» (Paula, operaria, 38 años).

Junto con el esfuerzo mayor desplegado en demostrar el «poder hacer» también se observa que se ven compelidas a demostrar el «saber hacer», visibilizando sus competencias y méritos para la tarea, reconociendo que ello implica un exceso de trabajo, comparativamente hablando.

«Ante cualquier par que tengas, puede ser cargo superior o paralelo, o de más abajo, con los cuales estás conversando, tienes que demostrarle que tienes nociones de lo que estás haciendo. La principal sensación, es que tengo que trabajar el doble (María, supervisora, 44 años).

Aun siendo jefas y con credenciales técnicas y cargo de toma de decisiones, igual son excluidas por su condición, en este caso de sexo. Pues una mujer en alto cargo sigue estando en un cuerpo rechazado, y esa es la razón para «descartarla» de ciertas tareas, cuya barrera no está objetivada en la carga, pero resulta «impresentable» para ser desempeñada por un cuerpo de mujer.

«Dije ¿te ayudo?, No, jefa usted no, ¿por qué no?. Llegó mi otro colega y le dijo: me pasas eso ... me dijo a ver ya, tráigase una bolilla de trenza. Se las pasé, le dije ¿tú crees que no soy capaz de eso?, no jefa, pero es que usted es mujer» (Luisa, supervisora, 39 años).

Grados de reconocimiento se logran con el tiempo, especialmente cuando el medio «se acostumbra» a su presencia y a observarlas desarrollando trabajos para las que se asume no están naturalmente calificadas. El hecho de ser las recién llegadas a faenas mineras, hace que este proceso sea incipiente, el que incluye demostrar igual o superior rendimiento físico y conocimientos. Un ejemplo es apoyar comprometida y solidariamente a 
compañeros enfermos, quienes en esa instancia pasan a tener un cuerpo menos fuerte, así ellas pueden evidenciar sus competencias.

«Me he terciado con compañeros enfermos ... él iba a ciertas cosas, le dije entonces quédate ahí, y como estoy en mejor estado físico, yo me muevo» (Ximena, operaria, 46 años).

La interpretación del «cuidado» frente a la intención de evitar que las mujeres realicen tareas físicas, tiene un sentido dual. Por un lado, es percibido como protección. Por el otro como sujeción, bajo el marco masculino dispuesto a infravalorar su trabajo («anda uno menos en el turno»). El primero como una versión benévola y, la segunda, perjudicial. Sin embargo, dos caras de una misma moneda que resta consideración y autonomía, aunque la primera aparente ser más amigable.

La disputa simbólica entre ser cuidada frente al peso físico y ejecutar el trabajo a la par, muestra los límites frente a los cuales las mujeres se posicionan en minería. Se trataría de fronteras demarcadas por el orden tradicional de género, con dosis de reflexibilidad en las mujeres, pero en los que se ve aún con distancia la percepción de un espacio apropiado. Otro elemento, que desafiaría el de la fuerza física de los cuerpos como eje discursivo de exclusión, es el avance en el desarrollo tecnológico, que puede generar cambios en la forma y ubicación de la ejecución de tareas, que tenderán a una menor dependencia del trabajo corporal e incluso de la presencialidad, pues implicarían la posibilidad de trabajo remoto y automatizado. Argumentando la reducción objetiva de impedimentos para que las mujeres puedan formar parte de equipos de trabajo en operaciones.

«Antiguamente las mujeres éramos vetadas por la fuerza, porque había cosas como abrir válvulas, cerrar válvulas, todo manual. Hoy en la empresa que estoy todo es tecnológico, las válvulas se abren con botones ... son muy pocas las manuales que van quedando, entonces la mujer si puede estar» (Carolina, operaria, 38 años).

Desde una perspectiva compleja podríamos señalar que las entrevistadas identifican cómo las diferencias de sexo, vinculadas al cuerpo biológico, entre hombres y mujeres, en este caso en el plano de las características fisiológicas e incluso ergonométricas para la realización de labores mineras (altura, peso, fuerza) son un límite a su inclusión. En el marco de las diferencias, ellas mismas buscan acciones de compensación (si un compañero está enfermo hacen la acción física para demostrar que pueden), así como reconocen que mayor tecnología contribuirá a reducir barreras en dicho plano (cerrar válvulas automatizadas).

Desde la perspectiva de género, analizamos cómo a partir de la diferencia sexual se han construido roles de género, los que se han estereotipado, operando de manera particular en las representaciones en minería. Las entrevistadas manifiestan que a partir de las menores valoraciones acerca de su cuerpo biológico, han respondido con (sobre) esfuerzo por superarlos. No es únicamente la menor capacidad objetiva en el desempeño del trabajo lo que genera la exclusión, puesto que logran finalmente demostrar capacidades para las tareas; sino que es el cuerpo biológico, como diferencia sexual, a partir de la cual se construyen representaciones de género, que actúa como frontera simbólica de exclusión, demarcada por el orden tradicional de género.

\section{Sexualización, transformaciones y resistencias frente a la presencia femenina}

Estudios previos han indicado que uno de los cambios incipientes a partir de la incorporación de mujeres en cargos no tradicionales, ha sido el clima laboral y el trato entre pares, pues se indica que ahora existe mayor respeto en la comunicación interpersonal; así como modulación del tono, modales o lenguaje -menos garabatos, groserías o chistes en doble sentido- (Caro, et al, 2019). Además, se han eliminado los calendarios o poster de mujeres semidesnudas, que en el pasado los trabajadores ubicaban en sus paredes. Sin embargo, pueden ser reacomodos de estereotipos, sin generar cambios sustantivos, sino sólo superficiales. Quienes llevan más tiempo atestiguan estos cambios.

«Eran muy brutos en realidad. La mujer como que trajo algo, produjo ese cambio donde el viejo tiene que preocuparse al hablar ... respeto, incluso hasta en las paredes... antes tu entrabas a una oficina y estaba lleno de mujeres piluchas, posters. Ya esas cosas no se ven» (Ana, supervisora, 52 años). 
No obstante, la presencia de las mujeres, como una otra diferente y desde una concepción estereotipada de su género y cuerpo, sigue siendo respondida con acciones y discursos que refuerzan la sobre sexualización, manifestándose de diferentes maneras. Está presente en comentarios denigrantes relativos a la vida afectiva y sexual de las mujeres, a que su presencia genera «tentación» masculina frente a situaciones de posible infidelidad, o que aluden a su estética (ropas, peinados, poses en fotografías, etc,), como si tuvieran el derecho y potestad de comentarla y calificarla. Evidenciando conductas «chismosas» o «copuchentas» en los hombres. Todos ellos enunciados violentos basados en la apropiación del cuerpo, que genera incomodidad, rabia y temor. Las nuevas generaciones no tienen necesariamente una mirada más progresista e igualitaria. Los relatos muestran reproducción de comportamientos, generando aprensión frente a la invasión de la vida privada o al hostigamiento.

«Hicieron una alusión a que me acosté con alguien ... rabia ... me molestó ... a todas las han involucrado alguna vez con alguien, una no puede por ejemplo saludar de besos, altiro igual empiezan a decir que te acostaste con él ... lo harán por tirarse flores ... hace un tiempo subí una foto en bikini a una red social y después todos la tenían, todos se la pasaban... corte nuevo... prenda nueva. Empiezan altiro, que estás buena mijita rica... Tenía miedo ... pensé que iba a ser mejor por el tema de la edad, porque hay gente más joven ... me desilusioné, como que acá se ve más el bullying, de los hombres de meterse en la vida de las mujeres, denigrarlas» (Marjorie, operaria, 24 años).

La denigración y cosificación del cuerpo, a través de comentarios inapropiados y violentos, revela relaciones de poder desiguales, al sentirse con el derecho a opinar y de paso, controlar lo que las mujeres visten, lucen o lo que comparten en redes sociales. Las trabajadoras se perciben «castigadas» por los comentarios sexualizados, así como reducidas e infravaloradas. Pues la referencia a ellas ya no es como colega de trabajo, sino como «mijica rica».

Frente a las situaciones experimentadas, la respuesta es contenida, de reclamo moderado, y de expresión tenue, como si de ellas dependiera mantener la distancia y controlar o evitar la pulsión sexual masculina. El resultado es tensión, puesto que se auto responsabilizan de poner límites y además hacerlo de manera «amable» para no perjudicar la relación con sus pares, manteniendo la armonía, pero que contiene un rechazo a la esencialización y cosificación.

«Soy compañera con ellos, somos equipo, pero es fácil que se te vayan para otro lado. Le das el brazo y empiezan a agarrarse el codo. El hombre siempre está tratando de ver la oportunidad. Ahí es donde una tiene que ser clara, sin ser desagradable, porque igual después vas a seguir compartiendo ... una tiene que fijar límites» (Ana, supervisora, 52 años).

En el cuerpo de las mujeres radicaría la seducción y recompensa del deseo de los hombres. Es la frontera del (des)honor femenino cuando está expuesto y es público. Se convierte en «honor» de los hombres. Algunas se resisten a convertir su sexo en parte constitutiva de su ser sujeto (yo soy compañera, somos equipo), y a que la diferencia sexual sea fundamento de las relaciones sociales. Su rechazo se expresa en los límites que ponen al intercambio sexual y simbólico con sus pares hombres, en un enfrentamiento al orden de género, no siempre directo.

La corporeidad de las mujeres es también utilizada como argumento para cuestionar ascensos femeninos. Se trata de discursos normalizados y estigmatizados, que relativizan el valor del mérito y las capacidades de las trabajadoras para asumir cargos de jefatura y de responsabilidad, y que, además, pueden dificultar su trabajo a no alcanzar el reconocimiento de su rol de liderazgo por sus pares y subalternos.

El intercambio socio simbólico con los hombres tiene efectos para el desarrollo de carrera de las mujeres en minería, el que se ve desestabilizado por los mismos mecanismos que lo permiten. El ascenso está permeado por la mirada de los otros que buscan su ilegitimidad, asumiendo que su posición no sería lograda por el mérito, sino dada por una situación extralaboral -se relacionó sexualmente con un jefe-. Situación que es experimentada como tensión, por tener ellas que «andar con cuidado» y evitar dobles interpretaciones a sus acciones. 
«¿ंTan poco tiempo que lleva?, es que le trae cosas al jefe o le anda coqueteando... si aquí, las mujeres ... Yo me he tenido que andar con mucho cuidado, porque mi marido trabaja aquí» (Angélica, operaria, 45 años).

En este caso, el marido actúa como figura que inhibe el intercambio y que incentiva el resguardo de ser cuestionada en su promoción laboral. Paradójicamente, el mérito como mecanismo de acceso a cargos de poder es para ellas una ficción, en tanto que su logro se ve marcado por percepciones prejuiciadas en torno a un eventual intercambio sexual, debilitando la legitimidad del ascenso.

\section{Discriminación y violencia sexual}

Las trabajadoras de todos los niveles identifican actitudes de discriminación sexual, explícitas e implícitas, más o menos hostiles, pero violentas al fin. Algunas mencionan haber conocido de estas prácticas antes de integrarse a las faenas, lo que las llevó a estar más alertas frente a su ocurrencia. El acoso sexual es una expresión extrema de violencia en el trabajo, que aparece como amenaza y evidencia en la experiencia propia o de otras compañeras.

«Cuando ingresamos acá e hicimos los cursos, nos hicieron siempre entender que, como que los hombres eran, como que te iban a acosar (sexualmente)» (Paula, operaria, 38 años).

El uso de la violencia radicaliza la tensión en lenguaje oral y cuerpo, así como revela muchas veces la incapacidad del primero para mostrar el dolor del segundo. Las emociones como la ira o miedo inscritas en el cuerpo de las mujeres aparecen sometidas y a veces negadas por un lenguaje racional. Por tanto, esas emociones tienen escasas posibilidades de reivindicarse como emoción subversiva que genere estrategias corporales de denuncia o protesta.

«Tratar de loca a una mujer es violento, y cuando lo hablan entre ellos también es violento ... si tú te quejas te dicen que eres grave» (Constanza, operaria, 40 años).

En la práctica, se reconocen situaciones explícitas de hostigamiento sexual físico y simbólico, acompañadas por amenazas basadas en una mayor estabilidad y posición de poder, vividas por ellas y por otras, en las que no se evidencia un papel activo de las empresas frente a las soluciones que se podrían presentar. De acuerdo con los testimonios, son las propias mujeres quienes usan mecanismos propios de rechazo, sin grandes resultados.

«Ella se hizo bastante amiga de alguien ... él confundió esa amistad con algo más. La empezó a toquetear. Ella le dijo oye para, si una cosa es que nos llevemos bien por WhatsApp y otra es que tu aquí me estés acosando,¿qué te has creído? ... ¿̇a quién le vas a decir? pero si aquí hablo... ¿quién te va a proteger a ti?, dijo. Si aquí tengo más peso, más cargo, llevo más años, tu eres recién a plazo fijo, nadie te va a creer, la dejó mucho tiempo así amenazándola... ella se sentía mal, entonces él pasaba por detrás y le pasaba rosando el trasero» (Tania, operaria, 24 años).

Aun cuando existe negación del acto y del cuerpo deseado (¿qué te has creído?) y de incomprensión por el acoso, se percibe en los relatos la existencia de culpa que las conduce a revisar sus propias prácticas objetivadas en redes compartidas de significado. En ocasiones se asume haber realizado «algo» que constituyó provocación, como, por ejemplo, estimular el deseo del hombre, fastidiarlos, suscitar desconfianza, en un movimiento pendular de acercamiento y alejamiento.

En casos de acoso sexual y laboral, existen elementos de desprotección y estigmatización que vulneran a las mujeres. Desprotección, porque está el miedo a no ser creída. Estigmatización, porque el hecho de levantar la voz puede conllevar a ser etiquetadas como mujeres «problema», pueden sufrir el rechazo de compañeros que la sancionan socialmente por ir «provocando» o ver dañada su reputación profesional.

«Si supiera que va a llegar a buen puerto, si siento que simplemente va a dejar un despelote, en donde va a quedar mi nombre basureado en todas partes, no lo hago, porque hay una cuestión de imagen que he trabajado años, para que a mí me tomen en serio como profesional» (Luisa, supervisora, 39 años). 
Los límites simbólicos de quién es víctima y victimario tienden a desaparecer, volviéndose categorías fluidas y complejas, ya que quien violenta puede ser inconsciente de su efecto y quien lo recibe vehiculizado en su cuerpo, tiende a sortearlos o evadirlos, de manera individual más que colectiva, probablemente porque desconfía del apoyo organizacional, considerando además la baja densidad de mujeres que obstaculiza la construcción de lazo social para actuar conjuntamente. Si el uso de la violencia en el primero pudiera interpretarse como no intencional, entonces, quien asume que debe actuar para impedir esta situación es quien tiene consciencia racional del lenguaje violento y del uso de la violencia. Es decir, sería responsabilidad de quien la padece. $\mathrm{Y}$ en cuanto las mujeres deciden frenarla recurriendo al uso de un lenguaje apropiado y un tono justo, es ahogada por la inconsciencia de los actos, sordo a los efectos que produce, generándose una doble validación del acto irreflexivo y una vuelta al estado inicial. De ahí se explica que el límite legal y la prescripción que impone la sanción normativa a quien ejerce la violencia denunciada, no serían suficientes para disuadir la reproducción de una cultura que violenta y discrimina a las mujeres.

El daño queda retenido en los cuerpos que lo han sufrido, convirtiéndose unas veces en silencio y, otras, en queja, pero siempre aprisionado como experiencia subjetiva y la mayor de las veces solitaria. Si bien la lucha contra la violencia que despliegan algunas mujeres es práctica social compartida cuando es denunciada, sigue siendo vivida por un cuerpo de mujer reconocible, pero que aparece ante quienes ejercen violencia como un cuerpo indiferenciado, sin identidad, lo que podría exacerbar el malestar de quien está sometida a ella.

\section{Cuerpos reproductivos: ciclo menstrual, embarazo y maternidad}

Otro de los focos a través de los cuáles se articula la discriminación y violencia hacia las mujeres en contextos mineros es el relativo a la capacidad reproductiva y los significados asociados para las mujeres, así como las etapas y procesos que implica. Abundan testimonios en torno al sufrimiento experimentado frente a prácticas y discursos violentos contra el cuerpo femenino reproductivo en minería; pues embarazarse, parir y amamantar es al mismo tiempo que banalizado, percibido como un problema. Los relatos señalan comentarios prejuiciosos o incluso denigrantes sobre su fertilidad y ciclo menstrual, entre otros procesos.

«Tener que aguantar que un colega le diga a otros en la reunión ¿por qué la supervisora se está haciendo el tratamiento de fertilidad en Santiago?. Mejor que venga pa’ acá, todos la ayudamos, entre todos ayudamos a que salga esa guagua» (Luisa, supervisora, 39 años).

Todos argumentos basados en discriminación y dominación masculina patriarcal que implica violencia simbólica. Se reconocen a sí mismas como destinadas a resignarse y ser discretas ante situaciones adversas y complejas, enfrentando barreras para subvertir la relación de dominación y, donde su sexualidad y procesos fisiológicos asociados a la anatomía de sus cuerpos se vuelven visibles.

«Es como en todos lados... si te quedas embarazada, que si no. Esas cosas son como típicas de prejuicios ... cuando una tiene el periodo (menstrual) ... he escuchado comentarios como que ya andai ... aquí se hace el comentario para la mujer que andai con el día, entonces ahí veo discriminación» (Ana, supervisora, 52 años).

En relación con la maternidad, otro aspecto relevante es que las decisiones que se toman en dicho plano son vividas como experiencias de menoscabo y riesgo a ser devaluadas como trabajadoras. La cultura minera, al igual que en otras industrias, pero en ésta se exacerba, no sólo por las condiciones estructurales de altura geográfica, distancia de la residencia o sistema de turnos, sino que fundamentalmente por las percepciones culturales imperantes, se considera el embarazo como un problema, o en lenguaje cotidiano, como confirma el testimonio, un «cacho». Confirmándose lo planteado en estudios previos, en torno a la existencia del «muro de la maternidad» (Minerals Council of Australia, 2013), esto es creer que las mujeres con hijos/as, aún más si son pequeños, no pueden ser buenas profesionales, considerado ésta como una de las principales limitantes a su estabilidad y ascenso laboral.

«Hay muchas mujeres y les pasa en todos lados, que se sienten, cuando quedan embarazadas, como cacho ....y en realidad no es un cacho, pero una se siente cacho» (Cecilia, supervisora, 39 años). 
La maternidad se aborda y trata como un problema individual y no social, aun cuando existe una serie de leyes de protección a los derechos de las trabajadoras en esta materia. El foco de preocupación de las jefaturas frente al embarazo, en minería, estaría en el reemplazo del turno, más que en cualquier otro aspecto. Además, es una experiencia reciente en una industria centenaria que nunca organizó sus sistemas de trabajo considerando ausencias o cambios de funciones temporales por razones de maternidad, sino que por accidentabilidad. En las entrevistadas se percibe el temor que experimentan por decir que están embarazadas, como si fuera ilegítima la decisión y legítima la crítica.

«La primera vez que quedé embarazada... cuando se lo planteamos a mi jefe, me dijo: ¿ ¿y cómo lo vamos hacer con el turno?... En realidad, me privé de tener hijos antes por el temor de cómo lo hacía con el trabajo... era mal mirado» (Francisca, supervisora, 55 años).

Por su parte, la experiencia de la maternidad de hijos/as pequeños/as, que presentan mayores necesidades de cuidado en materia de salud, como los controles pediátricos, es vivida por las mujeres con dolor y angustia, sobre todo cuando existen escasas redes de apoyo familiares o de amistad, y cuando hay baja comprensión de parte de jefaturas, incluso cuando son mujeres. La mayoría coincide en que tiene un alto costo psicológico, lo que se suma a la tendencia a la desvaloración laboral, pues ha sido utilizada como excusa para obstaculizar sus carreras y es percibida desde las trabajadoras como foco de situaciones de acoso laboral sexista vertical.

«Mi jefatura no podía entender que tus hijos se enfermaban, y que era la mamá que tenía que ir ... que no tenías una red de apoyo gigante... Lo pasé mal ... fui al psicólogo y me derivó al psiquiatra y estuve como 8 meses fuera de la faena con tratamiento psicológico, y todo esto fue por la mutual ... y después hubo una resolución, que efectivamente tuve acoso laboral de mi jefatura ... la que era mi jefa se fue a otro trabajo... te cuestionan todo, que por ley tú tienes que salir una hora antes de tu trabajo ... el conflicto es más con la mujer, el ser madre, ese es como el mayor conflicto que tiene la sociedad, en minería, ... nuestros hijos no van a ser chicos eternamente, no eternamente se van a enfermar» (Alejandra, operaria, 33 años).

\section{Cuerpos simbólicos: entre la masculinización y la pérdida de femineidad}

Las pocas mujeres que ingresan enfrentan una cultura patriarcal que se ve desafiada por su presencia. Estar físicamente, usar ropa y zapatos de seguridad, casco y antiparras, de estética y simbología masculina tradicional, y desarrollar funciones que contradicen roles y estereotipos tradicionales, genera en los hombres recelo, manifestado como burlas o envidias, expresado en rechazo, como parte del entramado de subjetividades que están a la base de resistencias masculina, por el miedo a una representación en igualdad.

«Cuando llegaba un camión nuevo, me mandaban a mí a probarlo, eso genera envidia, que te manden a un camión 0 kilómetros» (Angélica, operaria, 45 años).

La vivencia de la performatividad del cuerpo en minería genera discursos paradójicos y contrapuestos acerca de lo femenino, desde una visión dual tradicional. Recogimos testimonios de mujeres que perciben rechazo a la adopción de comportamientos, actitudes, formas de hablar o vestir asociadas a imágenes de la masculinidad hegemónica minera. Sin embargo, dichos rasgos, asumidos en la práctica por algunas mujeres, se explicarían como mecanismo de validación, pues se cree que por ese medio obtendrían respeto y consideración, como ocurre con los hombres. La paradoja está, en que, si bien se adoptan atributos masculinos como camino para ser reconocidas como par, simultáneamente son rechazados porque se «pierde» lo propio de la «feminidad» tradicional. En muchas se recoge y reivindica la necesidad de no abandonar el «toque femenino» en los espacios laborales y mantener la «esencia» de ser mujer.

«En esta industria hay muchas mujeres que tratan de parecer hombres ... para generar respeto, entonces al final como que en cierta forma pierden la esencia ... y así tratan brutamente a todo el mundo» (Pilar, supervisora, 26 años).

Esta inconsistencia y tensión experimentada, entre comportarse masculina y/o femenina a la vez, desde la visión dicotómica tradicional, nos lleva a cuestionar en sí mismo los significados de dicha dualidad. La estética 
y ritos de comportamiento que impone la condición agreste de la industria se materializa como valoración cuando es personificada por los hombres, pero cuando se trata de cuerpos de mujeres, lo mismo resulta despreciado y negado. Se trataría de un cuerpo no «validado», cargado negativamente, como ha sido presentado, y que puede convertirse en un objeto del cual se apropian simbólicamente los hombres para asegurar que las mujeres no tengan un estatus de sujeto igualitario.

Como parte de los atributos de la masculinidad tradicional que las mujeres rescatan como más relevante para adaptarse y resistir en un medio hostil, desde la perspectiva relacional, es demostrar un trato directo, rudo y duro, como factor protector, que describen se ubica más desde la racionalidad que desde la emocionalidad, desconociendo que la aspereza en el lenguaje también proviene desde dicha dimensión, pero de un rasgo emocional reconocido y validado para ser ejercido por los hombres.

«Para estar acá igual tenís que tener cierta personalidad y carácter más fuerte y ser ... no ahombrada, porque no es lo mismo ... no ser tan sensible, porque si no te mueres acá, te mueres de pena» (Ana, supervisora, 52 años).

En consecuencia, de acuerdo con la visión de las trabajadoras, se presenta una doble exigencia para poder ser reconocidas. Desde una dimensión material y simbólica se les exige masculinizarse, mostrando rudeza y fuerza física para equiparse a los varones; pero, al mismo tiempo, se les demanda no perder su femineidad -es decir, ser masculinas, pero no tanto-, lo que les lleva a reivindicar rasgos femeninos tradicionales. Finalmente, evidenciamos que les resulta muy complejo desempeñar este libreto dual exigido a las mujeres en minería, que, de acuerdo con la subjetividad de la cultura minera, les corresponde desempeñar. Pues nuevamente recae en ellas la responsabilidad de modelar el personaje que se les impone ejercer.

«La mujer que trabaja acá debe tener como un perfil ad hoc para trabajar con esta cantidad de hombres... debes tener carácter, tienes que hacerte respetar ... pero sin tampoco caer mal» (Ana, supervisora, 52 años).

\section{Discusión y conclusiones}

La disposición femenina de trabajar en un rubro no tradicional puede ser entendida como deseo de trastocar el ordenamiento simbólico y espacial definido por la sociedad patriarcal. Se trataría de cuerpos de mujeres que, en un escenario homosocial heteronormativo, trasgrede la división sexual tradicional del trabajo, imponiéndose. Pero, como hemos evidenciado sufre dolores y es permanentemente rechazado, violentado, exigido y cuestionado. Aun así, su presencia, abre la posibilidad de nuevos intersticios de lo femenino no contemplados previamente.

La visibilidad de cuerpos demandados, sexuados y compelidos revela un campo intersubjetivo en el que se comparten experiencias que están en los significados de la participación laboral de las mujeres, cargada de miedos de diversas naturaleza -a embarazarse, a tener que trabajar el doble, a ser acosadas- y de auto responsabilidad -de evitar, poner límites, evadir, lidiar-, relatada a través de diversas experiencias cotidianas individuales, sin que hasta ahora se perciban formas colectivas de abordarlas. Develando la tendencia a la privatización de la igualdad en entornos mineros, ya documentada (Mayes y Pini, 2010).

Aun cuando sean cuerpos dispuestos a soportar la misma carga de los hombres (altura geográfica, oscilación térmica, sistema de turnos alternados, desplazamientos), su presencia en faenas es percibida simbólicamente como amenaza, reafirmando la existencia de relaciones laborales desiguales en términos de sexo y género, basadas en el poder y dominación masculinos (Bourdieu, 2000). Concluimos que los discursos del entorno minero sobre la corporalidad femenina, son percibidos por las mujeres como límites para su participación y expresados como violencia simbólica, manifestada en la sexualización de sus cuerpos, desvalorización de sus aportes en áreas operativas, en tanto no es «medible» su rendimiento físico al igual que cuerpos masculinos, rechazo y banalización al cuerpo reproductivo, así como exigencia por personificar (Goffman, 1970) rasgos hegemónicos masculinos para «hacerse respetar» y resistir la hostilidad, pero sin 
«perder feminidad» en un sentido clásico. Todos elementos que cristalizan la desigualdad y valencia diferencial de los sexos (Héritier, 2002).

En los cuerpos se expresan las contradicciones del devenir del género, del que se percibe es acomodado según circunstancias para obtener pertenencia, ascenso o prestigio. Femenino y masculino tradicional, son rechazados y deseados al mismo tiempo. Esto permite, se vuelvan plurales, en un abanico de posibilidades (re)construidas, donde la prevalencia de un atributo (ser ruda) se exige sea acompañada de tintes tradicionales (no tanto, para no caer mal). Presentándose un conflicto simbólico que opera en la subjetividad. Situándose a contracorriente de normas sociales, recorriendo caminos desconocidos, que las lleva a preguntarse qué hacer y cómo ser.

Como se ha evidenciado, el control de los hombres hacia el cuerpo de las mujeres, como sexuación permanente y, el de las mujeres hacia el deseo estos, revela su carácter político (Butler, 2002, 2007), porque éste no es solo el portador del habitus -instrumento para trabajar, arma de defensa o ataque, o fuente de distracción, sino también se convierte en campo donde se producen luchas por la conservación o conversión de posiciones opuestas y complementarias de la diferencia sexual (Bourdieu \& Passeron, 1996) que impone el devenir del género y, con ello, la disputa por la (re)producción de un cuerpo legitimo (propio) e ilegítimo (dominado).

La idea del esfuerzo, recurrente en los discursos sociales chilenos (PNUD, 2017) se encarna literalmente en el cuerpo en este análisis contextualizado, pero a diferencia de esos discursos, los cuerpos de mujeres sentirían el control social -expresado en la mirada y juicio permanente- como una posibilidad de volverse visible a través del cumplimiento eficaz de las labores demandadas, otorgándole legitimidad a su presencia y satisfaciendo su deseo de pertenencia. Los cuerpos exigidos renovarían cotidianamente el sentido del trabajo como un recordatorio de sus aspiraciones y elecciones laborales. El esfuerzo tendría su recompensa en la integración y aceptación forzada.

\section{Agradecimientos}

Este artículo es producto del proyecto CONICYT FONDECYT Regular, No 1180590, 2018-2020 a quien agradecemos su financiamiento ${ }^{2}$.

\footnotetext{
Notas

${ }^{1}$ Las investigaciones incluyeron entrevistas a hombres, pero para este artículo se analizaron sólo a operarias y supervisoras de faenas.

${ }^{2}$ Adicionalmente se usaron algunas entrevistas de FONDEF ID16I10031, 2017-2018.
}

\section{Bibliografía}

Amorós, C. (1994). Feminismo, igualdad y diferencia. Ciudad de México. Programa Universitario de Estudios de Género. UNAM.

Angelcos, N. (2015). Disposiciones y resistencias a la participación sindical de las mujeres en la Gran Minería del Cobre en Chile. Documento de Trabajo, Universidad Diego Portales.

Angelcos, N. e Ísola, E. (2017). Violencia y táctica en los procesos de integración de las mujeres a la minería del cobre en Chile. Psicoperspectivas. Individuo y Sociedad, 16(2), 66-78. DOI: 10.5027/psicoperspectivas-vol16issue2-fulltext-1019.

Ayala, E. (2012). Mujer y minería: situación de la industria chilena. Tesis para optar al grado de Magíster en Gestión de Personas, Facultad de Economía y Negocios, Universidad de Chile. 
Arendt, H. (2005). La condición humana. Barcelona, España: Paidós.

Barrientos, J; Salinas, P.; Rojas, P. y Meza, P. (2009). Minería, género y cultura. Una aproximación etnográfica a espacios de esparcimiento y diversión masculina en el norte de chile. Revista de Antropología Iberoamericana, 4 (3), 385-408.

Bogino, M. y Fernández-Rasines, P. (2017). Relecturas de género: concepto normativo y categoría crítica. La Ventana, 5(45). Recuperado de: http://revistalaventana.cucsh.udg.mx/index.php/LV/article/view/5375

Bourdieu, P. (2000). La dominación masculina. Barcelona, España: Editorial Anagrama.

Bourdieu, P. y Passeron, J.-C. (1996). La reproducción. (segunda edición ed.) Barcelona, España: Distribuciones Fontamara.

Butler, J. (2002). Cuerpos que importan: sobre los límites materiales y discursivos del «sexo». Buenos Aires, Argentina: Paidós.

(2015). Cuerpos aliados y lucha política. Buenos Aires, Argentina: Paidós.

(2007). El género en disputa. El feminismo y la subversión de la identidad. Barcelona, España: Paidós

Caro, P., Ilabaca, P., Román, H., Armijo, L., Celis, K. y Meyer, L. (2019). Inclusión sustentable de mujeres en industrias masculinizadas. La minería en Chile. Santiago, Chile: Universidad Santo Tomás.

Curiel, O y Falquet J. (comps.) (2005). El patriarcado al desnudo. Tres feministas materialistas: Colette Guillaumin - Paola Tabet - Nicole Claude Mathieu. Buenos Aires, Argentina: Ediciones Brecha lésbica.

CCM - Consejo de Competencias Mineras (2019). Fuerza Laboral de la Gran Minería chilena 2019-2028. Diagnóstico y Recomendaciones. Santiago, Chile.

Charon, J. M. (1992). Symbolic Interactionism: An Introduction, An interpretation, An integration. Nueva Jersey, USA: Pearson Prentice Hall.

Goffman, E. (1959). La presentación de la persona en la vida cotidiana. Madrid, España: Amorrortu

(1970). Estigma: La identidad deteriorada. Madrid, España: Amorortu.

(1978) Gender Advertisements. Cambridge, MA: Harvard University Press.

(2007). Frame Analysis. Los marcos de la experiencia. Madrid, España: CIS.

Guillaumin, C. (2005). Práctica del poder e idea de Naturaleza. En O. Curiel y J. Falquet (comps.). El patriarcado al desnudo. Tres feministas materialistas: Colette Guillaumin - Paola Tabet - Nicole Claude Mathieu (pp. 1656). Buenos Aires. Ediciones Brecha lésbica.

Héritier, F. (2002). Masculino/ Femenino. El pensamiento de la diferencia. Barcelona: Ariel.

(2007). Masculino/ Femenino II. Disolver La Jerarquía. Buenos Aires, Argentina: Fondo de Cultura Económica.

Hirata, H. y Kergoat, D. (1997). La división sexual del trabajo. Permanencia y cambio. Buenos Aires, Argentina: Asociación Trabajo y Sociedad (Argentina), Centro de Estudios de la Mujer (Chile) y Piette del CONICET (Argentina). 
Ibáñez, D. (2008). El cierre del campamento de Chuquicamata y el traslado de su población a la ciudad de Calama: una nueva forma de vida para los mineros (Tesis de pregrado). Universidad Academia de Humanismo Cristiano. Santiago de Chile.

Jiménez, C.; Rojas, P. y Troncoso, R. (2014). Género, trabajo y subjetividad: el lugar de la mujer en la minería. Revista Persona y Sociedad, 28(3), 65-95.

Klubock, T. (1992). Sexualidad y proletarización en la mina El Teniente. Proposiciones, 21, 64-77

(1995). Hombres y mujeres en El Teniente: la construcción de género y clase en la minería chilena del cobre, 1904-1951. En Godoy, L.; Hutchinson, E.; Rosemblatt, K. Zárate, S. (eds.), Disciplina y desacato: construcción de identidad en Chile. Siglos XIX y XX (pp. 110-123). Santiago de Chile: Sur / CEDEM.

Kornblit, A. (2004). Historias y relatos de vida: una herramienta clave en metodologías cualitativas. En A. Kornblit (Ed.) Metodologías cualitativas en ciencias sociales (pp. 15-33). Buenos Aires: Editorial Biblos.

Lamas, M. (1986). La antropología feminista y la categoría «género». Nueva Antropología, 8(30), 173-198. Recuperado de: https://goo.gl/yRyYDs.

Mayes, R y Pini, B (2010) The 'Feminine Revolution in Mining': a critique, Australian Geographer, 41:2, 233-245, DOI: $10.1080 / 00049181003742336$

Minerals Council of Australia (2013). Workforce Gender diversity review White paper. «It’s Not Just a Program».

Pávez, I. (2018). Cuerpo feminista. Acoso y resistencia. Santiago, Chile: Forja.

Pavez, J. y Hernández, G. (2014). Regímenes de trabajo, relaciones laborales y masculinidades en la gran minería del cobre (norte de Chile). En X. Valdés, L. Rebolledo, J. Pavez, \& G. Hernández, Trabajos y familias en el neoliberalismo. Hombres y mujeres en faenas de la uva, el salmón y el cobre (págs. 167-263). Santiago: LOM.

PNUD, (2017). Desiguales. Orígenes, cambios y desafíos de la brecha social en Chile. Santiago de Chile: Uqbar Editores

Riquelme, V. (2011). ¿La maternidad castigada? Discriminación y malos tratos. Dirección del Trabajo/Departamento de Estudios, 10-70.

Rojas, C. (2014). Incorporación de la mujer en la minería el impacto de una cultura masculina, (Tesis de maestría), Universidad de Chile Facultad de Economía y Negocios, Santiago.

Rubin, G. (1975). El tráfico de mujeres. Notas sobre una economía política del sexo. En Revista Nueva Antropología, 3 (30), 95-145.

Ruiz, A. (2013). Género y trabajo: análisis de las representaciones simbólicas en el centro minero de Huanuni, Bolivia. Etnicex: Revista de Estudios Etnográficos, 5, 105-119.

Ruiz, J.I. (2003). Metodología de la investigación cualitativa. Bilbao: Universidad de Deusto.

Salinas, P., Barrientos, J. y Rojas, P. (2012). Discursos sobre la discriminación de género en los trabajadores mineros del norte de Chile. Atenea, 505, 139-158.

Salinas, P. y Barrientos, J. (2011). Los discursos de las garzonas en las salas de cerveza del norte de Chile. Género y discriminación. Polis Revista Latinoamérica, 10 (29),433-461

Salinas, P. y Cordero, C. (2016). Transformación de los liderazgos en la minería: gestión estratégica para incorporar 
mujeres en la industria. Revista Innovar, 26 (61).

Salinas, P. y Romani, G. (2014). Barreras de género en la minería chilena: una gestión estratégica. Revista latinoamericana de Administración, (1), 92-107.

(2016). Hegemonía masculina, freno en equipos mixtos en la minería chilena. Revista mexicana de Sociología 78 (3), 469-496.

Scott, J. (2008). Género e historia. México DF: Fondo de Cultura Económica.

Stefoni, M. (2005). Supervisoras en El Teniente: Mujeres en mundos masculinos (Tesis de maestría), Universidad de Chile, Santiago, Chile.

Tarrés, M. (coord..) (2004). Observar, escuchar y comprender. Sobre la tradición cualitativa en la investigación social. Ciudad de México: FLACSO - El Colegio de México. 